\title{
Guidelines And Advice For Successful Publication Provided By Journal Editors
}

Luke T. Miller, Fort Lewis College, USA

Alice Smith, Auburn University, USA

Elaine Labach, Fort Lewis College, USA

\begin{abstract}
Journal publication is an important indicator of research productivity for individual researchers, as well as academic institutions. However, for novice faculty members, the publication process can appear equivocal and daunting. If the academic does not actively engage themselves early in this process, then her or his career becomes an uphill (and sometimes insurmountable) battle. To assist the young academic, this study, sponsored by the National Science Foundation ADVANCE program, surveys journal editors representing numerous engineering fields. A 19-question web survey was e-mailed to 121 journal editors representing numerous engineering fields. Utilizing the ISI journal citation reports service, journal editors spanning aerospace, chemical, civil, environmental, industrial, and mechanical engineering disciplines were selected for initial contact. Of the 121 editors contacted, 40 usable responses (or a response rate of 33\%) were aggregated for this study. The survey responses were used to quantify publication timelines and acceptance rates and ascertain journal policies, advice for successful publishing, and gender differences.
\end{abstract}

Keywords: Journal publication, Article acceptance, Author guidelines

\section{INTRODUCTION}

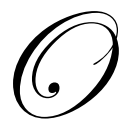

ne of the cornerstones of academia is archival journal publication. Publishing provides a communication channel for researchers within a field, a repository of important research efforts, and a recognition mechanism for researchers and institutions alike. However, despite its ubiquitous presence, the publication process remains both daunting and confusing to doctoral students and newer faculty members. The junior academic knows that not meeting archival journal publication standards in quality and quantity may result in her or his career being severely hindered. Other than this threatening consequence, new engineering faculty members have been offered little in the way of structured advice regarding a successful publication career.

The purpose of this paper is to summarize advice from accomplished academics that will assist both doctoral students and junior faculty members to achieve success in journal publications. More specifically, it summarizes a publication process survey sent to engineering journal editors that addresses a range of topics, including publication guidelines, acceptance rates, timelines, perceived gender differences, rejection factors, and open-ended counsel. The primary objective of this paper is to demystify the publication process and provide workable suggestions that young academics in engineering may use to successfully approach the journal hurdle.

\section{LITERATURE REVIEW}

To the authors' knowledge these efforts are a first attempt to provide publication advice to the engineering academic audience. This is not to say that the scientific literature is void of publication advice. In fact, several excellent resources are available. Texts summarizing the publication process from a general readership perspective include McCloskey (1987), Cantor (1993), Silverman (1999), and Luey (2002). Additionally, several articles directed towards economics, finance, management, and accounting researchers may also be found. Table 1 summarizes the literature on the publication process as it relates to the survey findings in engineering. As Table 1 
indicates, there are common attributes and advice for successful publication in any research discipline. In summary, successful papers are a contribution to the field, clearly written, and properly motivated.

Table 1. Summary of Current Publication Process Literature

\begin{abstract}
Publication Advice and Acceptance Indicators
Zivney and Bertin (1992) studied the performance of 1,127 finance PhD's over a 25-year period and their contribution to 128 different archival journals. Many key insights in terms of publication quantity and quality were identified and discussed. One interesting finding is the total number of publications that finance academics have actually achieved (versus perceived in the finance 'publish or perish' world). Of the 1,127 finance doctorates, the $90^{\text {th }}$ percentile number of publications after 5 years is 7 papers and after 20 years is 19 papers, the $75^{\text {th }}$ percentile after 5 years is 4 papers and after 20 years is 9 papers, and the $50^{\text {th }}$ percentile after 5 years is 2 papers and after 20 years is 4 papers. These findings suggest that "publishing one article per year in any finance-related journal over a prolonged period of time is a truly remarkable feat, met only by $5 \%$ of the graduates."

Mitenko and Diamond (1994) survey journal editors to examine the publication policies and practices of 25 finance journals. An aggregate acceptance rate across the 25 journals of approximately $20 \%$ was observed. Additionally, the following were identified (in order) as reasons for paper rejection: analytical errors, inappropriate journal submission, poorly written, lack of contribution, and inadequate explanation. The editors also provided the following advice to improve acceptance (in order): become familiar with the target journal, write concisely and clearly, clearly identify contribution to field, analyze data properly, and prepare a succinct abstract.

Henderson and Reichenstein (1996) surveys editors and reviewers in finance 'practitioner-oriented' journals concerning reasons for paper rejection. Listed in order frequency are: failed contribution, poor organization, poorly written, inappropriate journal, poorly linked results, and failure to motivate properly.

Chow and Harrison (1998) surveyed 119 influential accounting researchers to ascertain the most important factors for publishing success. Listed in order of frequency are: write clearly and concisely, utilize appropriate research skills, make a contribution, select a relevant topic, and remain persistent.

Henderson and Reichenstien (1998) acquire advice from the 50 most-cited authors in the top four finance journals. The following factors were identified for publication success (in order): better development and test of an existing idea or topic, ability to tell an economic story and relate quantitative results to that story, ability to find a gap in the literature as opposed to extending the research frontier, careful paper organization, and clearly written. The following rejection factors were also identified (in order): lack of contribution to the field, poor motivation, poor organization, poorly written, and failure to link results with economic story.

Koh (2003) explores how information system researchers view the journal review and publication process based on their professional status, institutional mission, and role orientation. He also addresses frequency of article submissions, acceptance/rejection rates, number of revisions required before publication, and publication outlets. Of the 122 survey respondents, an average acceptance rate of $60 \%$ was observed with $12 \%$ of papers accepted without revision, $27 \%$ accepted with one revision, $15 \%$ accepted with two revisions, and $6 \%$ accepted with more than two revisions. The 122 respondents have submitted 1,098 papers over the last three years, or on average three papers per year. The total review time averages 4 months with 2 months for the initial review and 2 months for subsequent reviews.
\end{abstract}

\title{
Gender Differences
}

Dwyer (1994) studied gender differences in the scholarly activities of accounting academics. The study indicated that women had significantly fewer publications in academic journals versus men. However, women and men received virtually equivalent number of total citations: this suggests that although women produce fewer papers than men, the total impact of women's papers is as great as the total impact of men's papers.

Streuly and Maranto (1994) study gender differences as they related to publication productivity and academic career advancement in the accounting area. They conclude that women are as productive as men when controlling for doctoral training and faculty appointment; thus, research performance should not be a barrier to the upward career mobility of women.

Collins, Parrish, and Collins (1998) study gender and the tenure track in the accounting field. Their key findings indicate little evidence of gender differences for women making tenure versus men. However, they did find that female faculty were significantly less likely to be hired at doctoral-granting institutions for their first position versus men. Thus, women are achieving same tenure rates as men, just at different types of institutions.

\section{SURVEY AND RESULTS}

The survey acquired information from successful publishing academics in the field of engineering. Although the acquired survey results are applicable to all academics, the National Science Foundation ADVANCE program funded these efforts to improve the recruitment and retention of women in engineering academia and to 
enhance career development of women engineering academics by addressing publications in refereed scholarly journals. A 19-question web survey was e-mailed to 121 journal editors representing numerous engineering fields. Utilizing the ISI journal citation reports service, journal editors spanning aerospace, chemical, civil, environmental, industrial, and mechanical engineering disciplines were selected for initial contact. Of the 121 editors contacted, 40 usable responses (or a response rate of $33 \%$ ) were aggregated for this study. The 40 respondents represent editorial experience from 33 engineering journals in seven disciplines. Table 2 contains the number of journals represented per engineering field, Appendix 1 lists the participating journals, and Appendix 2 contains the survey questions.

Table 2. Journal Editor Participants by Engineering Discipline

\begin{tabular}{|l|c|}
\hline \multicolumn{1}{|c|}{ Journal Discipline } & Number in Survey \\
\hline Chemical & 6 \\
\hline Industrial & 6 \\
\hline Civil and Environmental & 5 \\
\hline Engineering Management & 5 \\
\hline Electrical & 4 \\
\hline Mechanical & 4 \\
\hline Systems & 3 \\
\hline
\end{tabular}

The survey addresses a variety of publication topics. In general, it attempts to quantify the publication timeline and acceptance rates, and ascertain journal policies, advice for successful publishing, and gender differences. This discussion breaks the survey into three sections - guidelines and acceptance rates, publication timeline, and successful publication.

\subsection{Publication Guidelines}

Table 3 summarizes the publication policies and guidelines of the survey participants. Table 4 highlights the types of papers accepted in engineering journals:

- $\quad$ Of the 33 journals represented, only one of them requires a submission fee to initiate the review process.

- $\quad$ The majority of the journals send papers to three reviewers, with one journal using one reviewer and another using four reviewers.

- $\quad$ The preferred transparency is a single-blind process which implies the authors do not know their reviewers. Eighteen percent of the journals surveyed utilized a double-blind process wherein the authors' names are shielded from the reviewers and vice versa. It should be noted that the survey did not explicitly define the selection option 'neither'. As such, the $23 \%$ that selected 'neither' could imply complete transparency or lack of a journal policy.

- $\quad$ The average page count of an accepted paper is journal specific, with $59 \%$ of papers 10 to 25 pages in length.

- In Table 4, notice that analytical, theoretical, and conceptual developments equally comprise the majority of engineering journals' papers (roughly $60 \%$ ). Case studies, literature reviews, and educational material comprise an aggregate $30 \%$ of the material as well.

Table 3. Journal Policies and Guidelines

\begin{tabular}{|cc||cc||cc||cc|}
\hline \multicolumn{2}{|c|}{ Submission Fee } & \multicolumn{2}{c||}{ Usual Number of Reviewers } & \multicolumn{2}{c|}{ Review Transparency } & \multicolumn{2}{c|}{ Final Page Count } \\
\hline \multirow{2}{*}{$91 \%$} & Free & $3 \%$ & One & $56 \%$ & Single blind & $10 \%$ & $<10$ \\
$3 \%$ & $\$ 50-\$ 150$ & $18 \%$ & Two & $18 \%$ & Double blind & $18 \%$ & $10-15$ \\
$6 \%$ & NA & $78 \%$ & Three & $23 \%$ & Neither & $15 \%$ & $15-20$ \\
& & $3 \%$ & Four & $3 \%$ & NA & $26 \%$ & $20-25$ \\
& & & & & $15 \%$ & $>25$ \\
& & & & & & $15 \%$ & NA \\
\hline
\end{tabular}

$\mathrm{NA}=$ not available 
Table 4. Types of Papers in Engineering Journals

\begin{tabular}{|c|l|c|}
$\underline{\mathbf{R}} \mathbf{R} \mathbf{2}$ & $\begin{array}{c}\text { Percentage } \\
\text { of } \\
\text { papers }\end{array}$ \\
\hline 1 & Analytical developments & $20 \%$ \\
\hline 2 & Theoretical developments & $18 \%$ \\
\hline 3 & Conceptual developments & $17 \%$ \\
\hline 4 & Case studies & $11 \%$ \\
\hline 5 & Literature reviews & $10 \%$ \\
\hline 6 & Educational (or how-to) papers & $10 \%$ \\
\hline 7 & Responses to already published research & $7 \%$ \\
\hline 8 & Book reviews & $4 \%$ \\
\hline 9 & Position papers & $3 \%$ \\
\hline
\end{tabular}

Table 5 summarizes the acceptance rates of the surveyed participants' journals:

- A paper's acceptance rate (including subsequent revisions) ranges from less than $10 \%$ to greater than $40 \%$. Excluding the NA, $82 \%$ of the acceptance rates range from 20 to greater than $40 \%$. (Note: At the time of survey construction, acceptance rates greater than $40 \%$ were not considered very likely. Thus, we were unable to ascertain further information for this range.)

- A relatively small portion of papers are accepted without a major revision. Excluding the NA, approximately 3 in 20 papers will be accepted without a major revision.

- $\quad$ Editors may agree or disagree with a reviewer's recommendation. Quite surprisingly, editors agree with their reviewers only about $75 \%$ of the time. In other words, an editor will disagree with a reviewer's decision every 1 in 4 papers.

Table 5. Journal Acceptance Rates

\begin{tabular}{|c|c||c|c||c|c|}
\hline \multicolumn{2}{|c|}{$\begin{array}{c}\text { Overall } \\
\text { Acceptance Rate }\end{array}$} & \multicolumn{2}{|c|}{$\begin{array}{c}\text { Acceptance Rate } \\
\text { without Major Revision }\end{array}$} & \multicolumn{2}{c|}{$\begin{array}{c}\text { Editor } \\
\text { Concurrence }\end{array}$} \\
\hline & & & & & \\
\cline { 5 - 6 } & $<10 \%$ & $38 \%$ & $<5 \%$ & $5 \%$ & $<60 \%$ \\
$15 \%$ & $10-20 \%$ & $20 \%$ & $5-10 \%$ & $23 \%$ & $60-70 \%$ \\
$28 \%$ & $20-30 \%$ & $13 \%$ & $10-15 \%$ & $26 \%$ & $70-80 \%$ \\
$15 \%$ & $30-40 \%$ & $8 \%$ & $15-20 \%$ & $23 \%$ & $80-90 \%$ \\
$28 \%$ & $>40 \%$ & $5 \%$ & $>20 \%$ & $10 \%$ & $90-100 \%$ \\
$13 \%$ & NA & $18 \%$ & NA & $13 \%$ & NA \\
\hline
\end{tabular}

\subsection{Publication Timeline}

Table 6 summarizes publication processing time information:

- $\quad$ The editor spends several months processing, reviewing, and distributing the paper to reviewers. A submitted paper may be sent out for review by the editors anytime up to 5 months from receipt, with the largest percentage sent out after 1 to 3 months.

- $\quad$ Most of initial peer reviews require less than 6 months.

- Upon completion of all reviews and revisions, the majority of editors make a final accept/reject decision in less than one month. 
- $\quad$ The total review decision time (including all revisions) ranges from less than 6 months to 2 years. Approximately, $80 \%$ of all papers require 6 to 18 months before an acceptance decision is reached.

Table 6. Publication Timeline (in Months)

\begin{tabular}{|c|c||c|c||c|c|}
\hline \multicolumn{2}{|c|}{$\begin{array}{c}\text { Initial } \\
\text { Editor Review }\end{array}$} & \multicolumn{2}{c|}{$\begin{array}{c}\text { Initial } \\
\text { Peer Review }\end{array}$} & \multicolumn{2}{c|}{$\begin{array}{c}\text { Editor } \\
\text { Decision }\end{array}$} \\
\hline & & & & & \\
\cline { 2 - 2 } \cline { 5 - 6 } & $<1$ & $17 \%$ & $<2$ & $74 \%$ & $<1$ \\
$23 \%$ & $1-3$ & $43 \%$ & $2-4$ & $11 \%$ & $1-3$ \\
$3 \%$ & $3-5$ & $26 \%$ & $4-6$ & $3 \%$ & $3-5$ \\
$3 \%$ & $5-7$ & $6 \%$ & $6-8$ & $9 \%$ & $5-7$ \\
& NA & $3 \%$ & $>8$ & $3 \%$ & NA \\
\hline
\end{tabular}

\begin{tabular}{|c|c||c|c|}
\hline \multicolumn{2}{|c|}{$\begin{array}{c}\text { Total Review Time } \\
\text { (including revisions) }\end{array}$} & \multicolumn{2}{|c|}{$\begin{array}{c}\text { Accepted Papers } \\
\text { to Print }\end{array}$} \\
\hline & & & \\
\hline $14 \%$ & $<6$ & $34 \%$ & $<6$ \\
$43 \%$ & $6-12$ & $49 \%$ & $6-12$ \\
$34 \%$ & $12-18$ & $9 \%$ & $12-18$ \\
$3 \%$ & $18-24$ & $3 \%$ & $18-24$ \\
$6 \%$ & NA & $6 \%$ & NA \\
\hline
\end{tabular}

\subsection{Successful Publication}

Editors selected the top five factors contributing to a rejected journal paper, in order of observed frequency. Table 7 summarizes the responses. The 'number of times selected' indicates the total number of times a rejection factor was identified in the top 5 reasons for rejection. The average importance rating is an indicator of the significance the respondent placed on the rejection factor. The rating is based on a 5-point scale with the most likely reason receiving a five. Thus, a rating of a 5 indicates the respondent selected the rejection factor as the number one reason for rejection. The overall importance rating multiplies the 'number of times selected' and the 'average importance rating' to provide an aggregate perspective. Finally, the overall importance rating is used to proxy the percent of papers rejected per rejection factor by proportioning the overall importance rating. For example, the rejection factor 'lack of contribution to the field' was selected in the top 5 reasons for publication rejection by all 40 survey respondents. It received a rating of 4.77 on a 5-point scale, an overall importance rating of 191, and is the factor accounting for one-third of all rejected papers.

Table 7. Reasons for Paper Rejection

\begin{tabular}{|c|l|c|c|c|c|}
\hline \multicolumn{2}{|l|}{ Rank } & \multicolumn{1}{|c|}{$\begin{array}{c}\text { Rumber } \\
\text { of times } \\
\text { selected }\end{array}$} & $\begin{array}{c}\text { Average } \\
\text { importance } \\
\text { rating }\end{array}$ & $\begin{array}{c}\text { Overall } \\
\text { importance } \\
\text { rating }\end{array}$ & $\begin{array}{c}\text { Percent of } \\
\text { papers } \\
\text { rejected }\end{array}$ \\
\hline & & & & & \\
\hline 1 & Lack of contribution to the field & 40 & 4.77 & 191 & $32 \%$ \\
\hline 2 & Poorly framed research problem & 35 & 3.07 & 108 & $18 \%$ \\
\hline 3 & Lack of theoretical/empirical development & 29 & 3.23 & 94 & $16 \%$ \\
\hline 4 & Poor paper organization and presentation & 29 & 2.56 & 74 & $12 \%$ \\
\hline 5 & Inadequate conclusions & 23 & 2.17 & 50 & $8 \%$ \\
\hline 6 & Inadequate literature review & 18 & 1.94 & 35 & $6 \%$ \\
\hline 7 & Other reason & 11 & 2.46 & 27 & $5 \%$ \\
\hline 8 & Unclear introductory section & 7 & 1.75 & 12 & $2 \%$ \\
\hline 9 & Excessive length & 8 & 1.00 & 8 & $1 \%$ \\
\hline
\end{tabular}




\subsection{Open-ended Counsel}

The respondents were asked to openly respond to the following two questions:

- What is your description of an ideal journal paper?

- What advice would you provide young researchers as they prepare to begin the journal publication process?

In an effort to quantify these open-ended responses, we organized them according to subject category and recorded the frequency of occurrence. Figure 1 summarizes the frequency of each category referenced by the survey respondents. Additionally, representative quotes are cited for each subject category.

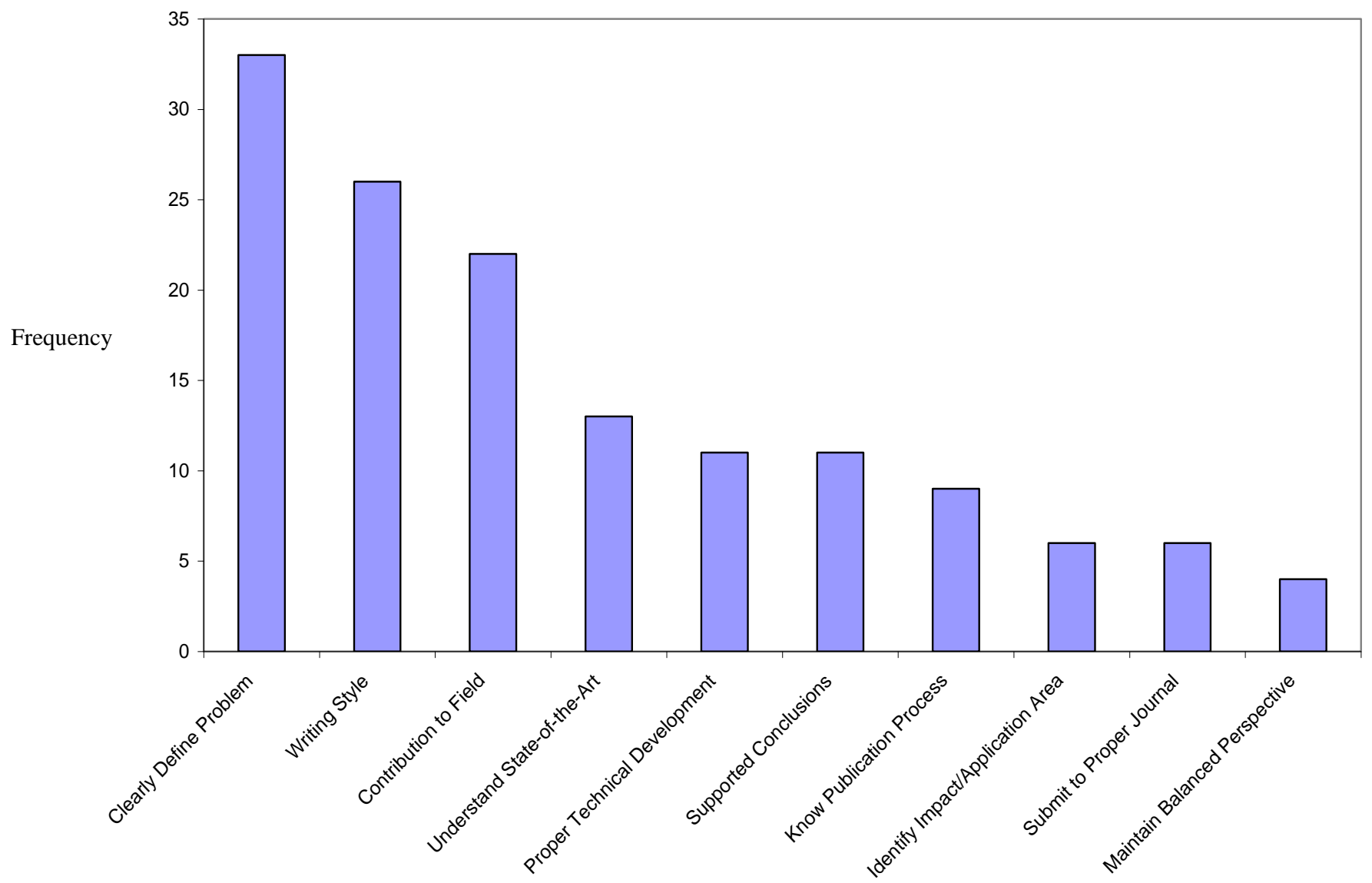

Figure 1. Summary of Open-Ended Responses Concerning Successful Publication

1. Clearly Define Problem

"Well-defined problem statement is key"

"Clearly define the problem being studied"

"Frame an interesting problem"

"The paper starts with an interesting and well-motivated research question" 
2. Writing Style

"Young researchers must develop the art of being able to present ideas clearly and concisely to a general technical readership."

"Well structured and organized to accepted professional journal formats; well written so that it is clear and there is no ambiguity; concise but thorough"

"Clear, concise, and readable to people both inside and outside the specific area"

"Clear and concise reporting of the subject material"

3. Contribution to Field

"An ideal journal paper should contribute to its field"

"Innovative ideas that provide a significant contribution"

"Makes a clear and original contribution"

4. Understand State-of-the-Art

"Based on the most current ideas with a very good literature survey"

"The paper should have a solid hypothesis based on previously published papers"

"Well contrasted to current literature work"

5. Proper Technical Development

"Use appropriate methodology to test the research question"

"Experimental design should be clearly defined in order to enable the reader to reproduce the method"

6. $\quad$ Supported Conclusions

"Clearly explains the solutions and draws clear conclusions based on results actually shown in the paper" "Appropriate technical basis for the conclusions"

\section{Know Publication Process}

"Young researchers must develop skills in revising manuscripts to incorporate reviewer suggestions" "Understand the time interval between submission and publication"

8. Identify Impact/Application Area

"Identify at least one example of where it could have an impact or application"

"Contain an adequate indication of the likely impact area or extent of the analysis, observation, or insight"

9. Submit to Proper Journal

"The biggest challenge is identifying what journals are appropriate for different types of papers"

"Understanding the different journals in a given discipline and aligning the research to the specific audience of the journal"

10. Maintain Balanced Perspective

"Young researchers lack an understanding of the big picture. Therefore, they have trouble placing their work in perspective."

"Learn to properly divide time between teaching, research activities, service activities, and publication responsibilities" 


\subsection{Gender Differences}

In order to identify perceived gender aspects of the publication process, the survey participants were asked the following questions:

1. "Have you observed any barriers in the publication process that impact the acceptance of women researchers' papers? If so, would you elaborate?"

None of the survey respondents have witnessed gender barriers in the publication process. Several comments are worth noting:

- $\quad$ Five respondents stated that barriers are high for everyone to include gender, nationality, and ethnic background.

- $\quad$ Two respondents stated that women have higher acceptance rates versus men in the journals that they manage.

- One respondent stated that even though women face real or imaginary barriers in the work environment, these barriers do not exist in the publication process.

2. "What, if any, additional or unique advice would you give to women researchers (versus men) concerning a successful publication practice?"

The majority of respondents stated that advice for women researchers would be the same for men researchers. One respondent sums it best "We are just looking for great papers". However, several respondents had additional comments:

- $\quad$ Four respondents advise women researchers to be aggressive and persistent and not to take criticism personally.

- $\quad$ One respondent states that women tend to write more tentatively and less arrogantly than men.

- $\quad$ One respondent recommends that women should exploit their better skills in organization and methodical work (versus men).

- $\quad$ One respondent recommends women researchers to use initials on submitted papers instead of complete names.

- $\quad$ One respondent recommends that journals should adopt a double-blind review process.

\section{GUIDELINES FOR AUTHORS}

In addition to the direct advice and results presented above, this section extrapolates pertinent information and develops guidelines concerning submitted papers, publication processing time, and the number of papers an academic should have under review. Note that this extrapolation utilizes the 'average' inputs from the survey respondents in terms of acceptance factors, timelines, and rates. As such, this information should be viewed as approximate guidelines and recommended policies, with individualized recommendations dependent upon journal publication in engineering discipline, institutional policies, and personal goals.

Utilizing information from Tables 5 and 7, Table 8 provides the expected paper acceptance outcome based on 100 submitted papers. Of the 100 papers submitted, 35 papers will be accepted for archival journal publication with 10 accepted without major revision. The remaining 65 papers will not be accepted for publication with 43 papers rejected for research related issues and 22 papers rejected for presentation concerns. Twenty-one papers will be rejected for lack of contribution to the field, 12 papers will be rejected for a poorly framed research problem, and 10 papers will be rejected for lack of theoretical/empirical development. Concerning presentation, 8 papers will be rejected for poor paper organization and presentation, 5 papers will be rejected for inadequate conclusions, 4 papers rejected for an inadequate literature review, 1 paper for an unclear introductory section, 1 paper for excessive length, and 3 papers for other reasons. 


\begin{tabular}{|c|c|}
\hline Accepted Papers & 35 \\
\hline Accepted without major revision & 10 \\
\hline Accepted with revisions & 25 \\
\hline Rejected Papers & 65 \\
\hline Research Factors & 43 \\
\hline Lack of contribution to the field & 21 \\
\hline Is it really a contribution? & \\
\hline Is the problem clearly defined? & \\
\hline Do you clearly understand state-of-the-art? & \\
\hline Is your poor writing style 'hiding' your contribution? & \\
\hline Are you submitting your paper to the 'right' journal? & \\
\hline Have you properly identified an impact area or application area? & \\
\hline Poorly framed research problem & 12 \\
\hline Is it a novel and interesting research question? & \\
\hline Is the problem clearly and concisely defined? & \\
\hline Is the approach logical and well-organized? & \\
\hline Is state-of-the-art clearly contrasted with literature? & \\
\hline Lack of theoretical/empirical development & 10 \\
\hline Are there analytical or mathematical errors? & \\
\hline Are you using an appropriate approach? & \\
\hline Does your approach agree with accepted theories? & \\
\hline Does your development link the problem statement with the conclusions? & \\
\hline Presentation Factors & 22 \\
\hline Poor paper organization and presentation & 8 \\
\hline Is the presentation clear, concise, and well-organized? & \\
\hline Are you properly linking the introduction, development, and conclusions? & \\
\hline Inadequate conclusions & 5 \\
\hline Do you have appropriate technical basis for conclusions? & \\
\hline Do your conclusions finish the 'story' that began with the problem statement? & \\
\hline Inadequate literature review & 4 \\
\hline Is your understanding of state-of-the-art clearly demonstrated? & \\
\hline Unclear introductory section & 1 \\
\hline Do you clearly and concisely get to the 'point'? & \\
\hline Excessive length & 1 \\
\hline Are all those pages really necessary to tell a clear and concise story? & \\
\hline Other reason & 3 \\
\hline Are you addressing the reviewer's comments? & \\
\hline Are you spending too much time on a marginal contribution? & \\
\hline
\end{tabular}


Under each rejection criteria, a checklist is provided to assist the young academic in preparing a research paper. Using Table 8, it is anticipated an author can mitigate some of the rejection factors by focusing on paper presentation and development. For example, if an author can ensure a properly defined research problem, and adequate paper organization, conclusions, literature review, and introduction, then the author's acceptance rate could potentially go from $35 \%$ to $65 \%$. This agrees with the qualitative responses summarized in Figure 1 wherein the two most important factors that journal editors identified in their open-ended responses are clearly defining the problem and good writing style. Thus junior academics should realize that no matter the quality of the actual research, the author can and should improve the presentation of the material. If the research is sufficient, then a quality presentation will shed light on the contribution. If, however, the research is insufficient, then a clear presentation will allow the reviewers to provide meaningful and helpful comments to improve the paper. In either case, a clear presentation is always beneficial.

The average publication timeline is constructed in Figure 2. Results from Table 5 indicate the average initial editor review process takes 3 months, the first peer review process takes 4 months, subsequent revisions take 3 months, and the final editor decision takes 1 month. Assuming it takes time $T_{l}$ to research, develop, and write a good paper, and $T_{2}$ to prepare the necessary paper revisions, the entire paper processing time from initial development to final acceptance takes $\left(T_{1}+T_{2}+11\right)$ months. Assuming a reasonable estimate for $T_{1}=6$ months and $T_{2}=3$ months, the entire processing time for one paper is 20 months. Novice researchers need to be cognizant of this lengthy timeline, especially considering that tenure decisions usually occur at the end of year 5. A one- or two-year delay in research and authorship responsibilities can irreparably harm an academic career. Figure 2 also stresses the importance of extracting papers from the dissertation and/or collaborating with colleagues. The quicker a good paper "hits the street, the faster it can drive home."

Finally, given all of these estimates of paper processing time, acceptance rates, and research goals, the following is a simple expression for the total number of papers an author should have under review at all times in order to accomplish his/her research agenda. Denote $P T$ as the total paper processing time (from initial research to acceptance decision), $T H$ as the career time horizon of interest (e.g. tenure clock), $R$ as the average acceptance rate in the target journals, and $G$ as the goal number of papers to have accepted (not necessarily in-print) at the end of the time horizon. Then the number of papers an author should have under review at all times, $X$, is equal to:

$$
X=\frac{G * P T}{R^{*} T H}
$$

For example, assume a base-case scenario with an acceptance rate of $R=35 \%$, total paper processing time of $P T=$ 20 months, career time horizon of $T H=60$ months, then $X=0.95 G$. Thus, if your goal is 10 accepted publications at the end of five years, you will need to have almost 10 papers under review at all times. Using these reasonable estimates, the $X$ and $G$ are for practical purposes related one-to-one. (Note that $X$ does not mean an author should write 10 new papers every 20 months. It infers only that 10 different papers should be under review at all times. If and when a paper gets accepted, then a new paper needs to replace the accepted paper. If a paper gets rejected, then revise appropriately and submit to a different journal. This resubmitted paper to a different journal counts as one of the 10 papers under review.) If it takes the initial year to produce the first set of papers under review, then $T H=48$ months, and $X=12$ papers.

Equation (1) may or may not be interpreted literally. Its purpose is to stress the importance of having numerous papers submitted at all times. Additionally, it should point to: (1) Beginning the publication process as soon as possible, and (2) Clearly defining the problem with a good writing style in order to potentially increase the acceptance rate $(R)$ and decrease $X$. Figures 3 and 4 plot the base-case scenario of $X$ as function of time horizon and acceptance rate, respectively. In Figure 3, notice how delaying the publication process drastically impacts the ability to meet the target goal of publications at the end of the time horizon. If $G=10$ papers, then $X=16$ papers for $T H=$ 3 years versus the base-case $X=10$ papers. Thus, the $60 \%$ increase in $X$ greatly reduces the probability of accomplishing the target goal. Figure 4 plots the effect of improving the acceptance rate by focusing on clearly defining the problem with a good writing style. For discussion purposes, assume if a poorly written paper has $R=$ $20 \%$, then $X=17$ papers. Whereas, if a well written paper has $R=50 \%$, then $X=7$ papers. Observe the inverse 
relationship between quality versus quantity of work. The greater the quality of work leads to a greater acceptance rate and a smaller number of papers to submit in order to achieve the target goal.

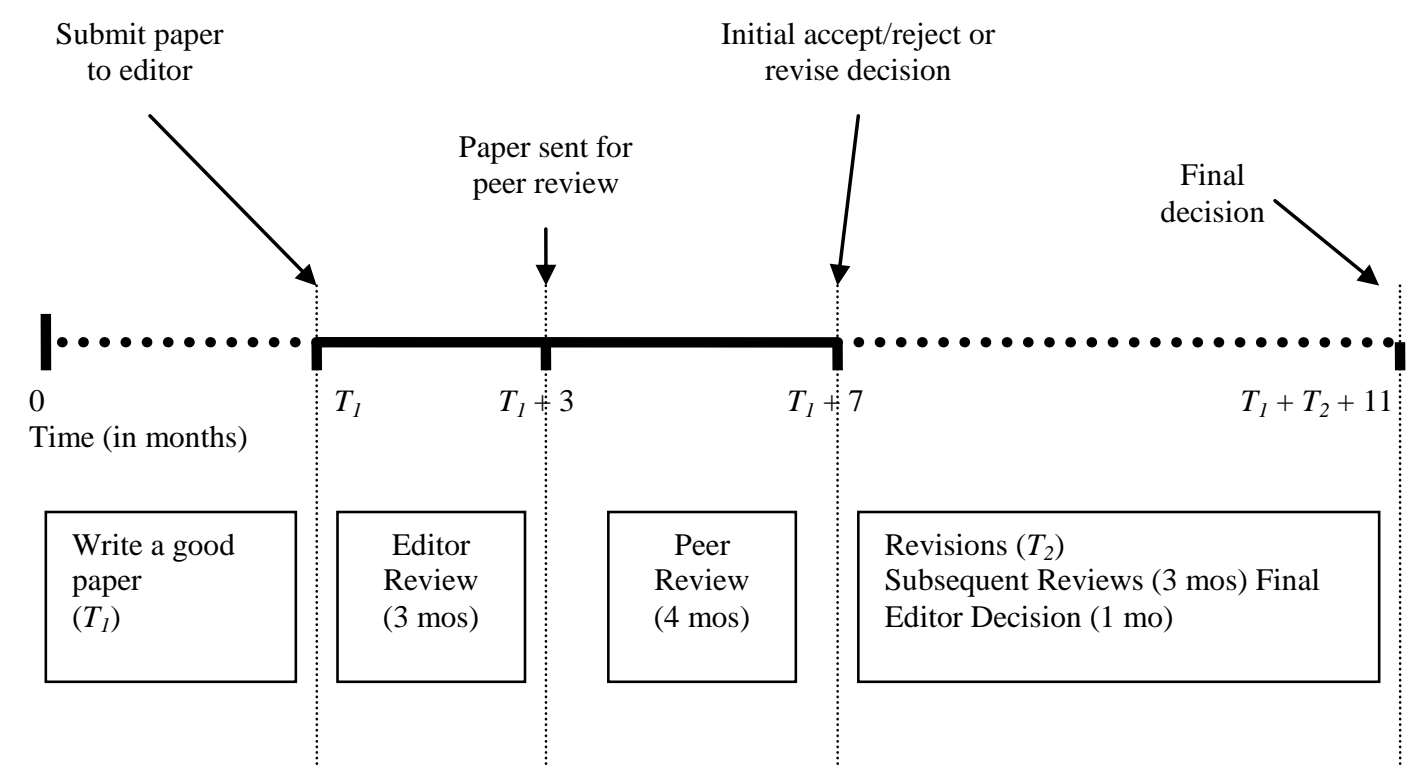

Figure 2. Expected Publication Processing Timeline

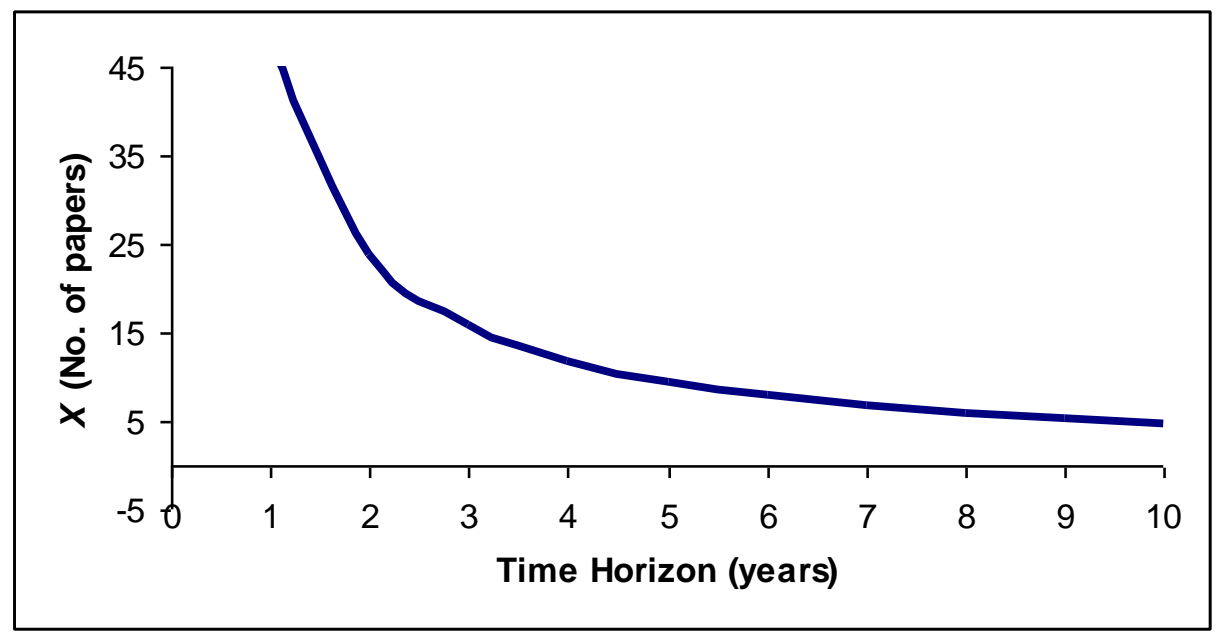

Figure 3. $\mathrm{X}$ as a Function of Time Horizon 


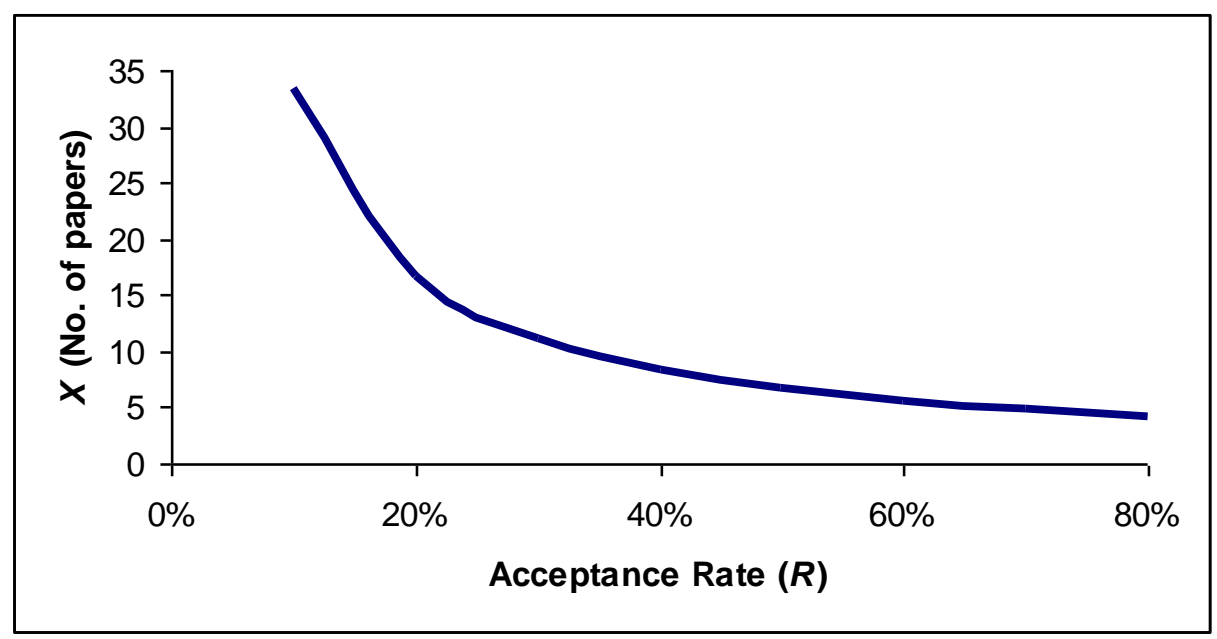

Figure 4. X as A Function of Acceptance Rate

\section{CONCLUDING REMARKS}

This study surveyed journal editors from a variety of engineering disciplines in order to quantify the publication process and capture expert advice concerning a successful publication career for beginning academics. Topics discussed included publication guidelines, acceptance rates, timelines, gender differences, and open-ended counsel. These results quantify the publication timeline and encourage active and quality research early in the academic career. The information should be used to help new academics develop effective research strategies and improve the effectiveness of research efforts.

The importance of clearly defining the research problem and good writing cannot be emphasized enough. It is believed that proper motivation and clear writing, combined with a research contribution, are the crux to successful publication. The ability to tell a unique 'research story' and incorporate sound quantitative results are the key to this process. The ability to effectively communicate ideas to others underlies the entire publication process.

Note that some of these results may not be generalized for researchers in all engineering disciplines. Although the initial survey was emailed to representatives from all engineering disciplines, the composition of the survey respondents may not accurately reflect all engineering fields. Finally, the survey may have unforeseen biases in question construction and we may have interpretations not representative of all engineering researchers.

\section{ACKNOWLEDGEMENTS}

This research was funded by the National Science Foundation ADVANCE program \#SBE-0123493.

\section{AUTHOR INFORMATION}

Luke Miller is an Assistant Professor of Finance in the School of Business Administration at Fort Lewis College. After attending the University of Virginia for his undergraduate degree in Systems Engineering, he served as an instructor and program manager in the U.S. Air Force. Completing his Masters and PhD in Financial Engineering from Auburn University, Dr. Miller served as a faculty member in the School of Business Administration at the University of San Diego where he taught quantitative and financial economic courses. His consulting, teaching, and research interests span all areas of business valuation to include, but not limited to: financial planning, capital budgeting, replacement analysis, capital rationing, security analysis, and risk management. 
Alice E. Smith is Professor and Chair of the Industrial \& Systems Engineering Department at Auburn University. Dr. Smith has degrees in engineering and business from Rice University, Saint Louis University and University of Missouri - Rolla. Her research in analysis, modeling and optimization of manufacturing processes and engineering design has been funded by NASA, the National Institute of Standards (NIST), Lockheed Martin, Adtranz (now Bombardier Transportation), the Ben Franklin Technology Center of Western Pennsylvania and the National Science Foundation (NSF), from which she was awarded a CAREER grant in 1995 and an ADVANCE Leadership grant in 2001.

Elaine Labach is an Assistant Professor of Management at Fort Lewis College. She graduated with a PhD in operations management from Indiana University and has had a parallel career in academia as well as in business. She has served as a faculty member with other universities and has held management positions with several manufacturing and service firms. Her main research interests are service operations, and the development and use of case studies.

\section{REFERENCES}

1. $\quad$ Cantor, J., A Guide to Academic Writing. London, Greenwood Press, 1993.

2. Chow, C., and P. Harrison, "Factors contributing to success in research and publications: insights of influential accounting authors," Journal of Accounting Education, Vol. 16, 1998, pp. 463-472.

3. Collins, A., B. Parrish, and D. Collins, "Gender and the tenure track: some survey evidence," Issues in Accounting Education, Vol. 13, No. 2, 1998.

4. Dwyer, P., "Gender differences in the scholarly activities of accounting academics: an empirical investigation," Issues in Accounting Education, Vol. 9, No. 2, 1994.

5. Henderson, G., and W. Reichenstein, "Writing for professional journals," Financial Practice \& Education, Spring/Summer 1996, pp. 65-73.

6. Henderson, G., and W. Reichenstein, "Advice from the elite of finance," Financial Practice \& Education, Spring/Summer 1998, pp. 51-59.

7. Koh, C., "IS journal review process: a survey on IS research practices and journal review issues," Information \& Management, Vol. 40, 2003, pp. 743-756.

8. Luey, B., Handbook for Academic Authors, $4^{\text {th }}$ ed. Cambridge, UK, Cambridge University Press, 2002.

9. McCloskey, D., The Writing of Economics. New York, Macmillan Publishing, 1987.

10. Mitenko, G., and J. Diamond, "Publication policies and practices of major finance journals: a survey of editors," Financial Practice \& Education, Fall/Winter 1994, pp. 88-92.

11. Silverman, F., Publishing for Tenure and Beyond. London, Praeger, 1999.

12. Streuly, C., and C. Maranto, "Accounting faculty research productivity and citations: are there gender differences?” Issues in Accounting Education, Vol. 9, No. 2, 1994.

13. Zivney, T., and W. Bertin, "Publish or perish: what the competition is really doing," Journal of Finance, Vol. 47, No. 1, 1992, pp. 295-329. 


\section{APPENDIX 1 - JOURNAL PARTICIPANTS}

\section{Chemical}

AICHe Journal

Industrial and Engineering Chemistry Research

Journal of Membrane Science

Physics and Chemistry of Liquids

Physics of Fluids

Reviews in Chemical Engineering

\section{Industrial}

Engineering Economist

Human Factors

IIE Transactions

Journal of Manufacturing Systems

Naval Research Logistics

Transportation Science

\section{Civil and Environmental}

Journal of Environmental Engineering

Journal of Environmental Quality

Journal of Materials in Civil Engineering

Journal of Soil and Water Conservation

Journal of Water Resources Planning and Management

\section{Engineering Management}

IEEE Transactions on Engineering Management

Journal of Engineering Education

Journal of Operations Management

Management Science

Manufacturing and Service Operations Management

\section{Electrical}

IBM Journal of Research and Development

IEEE Transactions on Industrial Electronics

IEEE Transactions on Semiconductor Manufacturing

Journal of Computers and Structures

\section{Mechanical}

IEEE Transactions on Advanced Packaging IEEE Transactions on Computer Aided Design

Journal of Applied Mechanics

Journal of Structural Engineering

\section{Systems}

IEEE Transactions on Evolutionary Computation

IEEE Transactions on Neural Networks

IEEE Transactions on Reliability 


\section{APPENDIX 2 - SURVEY QUESTIONS}

\section{Publication Process Questions}

1. On average, what percent of papers are eventually accepted at your journal?
a. less than $10 \%$
b. $10-20 \%$
c. $20-30 \%$
d. $30-40 \%$
e. greater than $40 \%$

2. What percent of papers get accepted without requiring a major revision?
a. less than $5 \%$
b. $5-10 \%$
c $10-15 \%$
d. $15-20 \%$
e. greater than $20 \%$

3. What is the standard number of reviewers to assign to one paper?
a. one
b. two
c. three
d. four
e. five

4. What percent of the time do you agree with the reviewer's decision recommendation?
a. less than $60 \%$
b. $60-70 \%$
c. $70-80 \%$
d. $80-90 \%$
e. $90-100 \%$

5. What is the average length (in pages) of an accepted journal paper?
a. less than 10 pages
b. $10-15$ pages
c. 15-20 pages
d. 20-25 pages
e. greater than 25 pages

6. Is your review process single blind, double blind, or neither?
a. Single blind
b. Double blind
c. Neither

7. What submission fee does your journal charge?
a. Submission is free
b. less than $\$ 50$
c. $\$ 51-\$ 150$
d. $\$ 151$ - $\$ 250$
e. greater than $\$ 250$ 


\section{Publication Content Questions}

1. Select five of the following factors that contribute to a rejected journal paper. Please rank in order of frequency and/or importance (1-5).

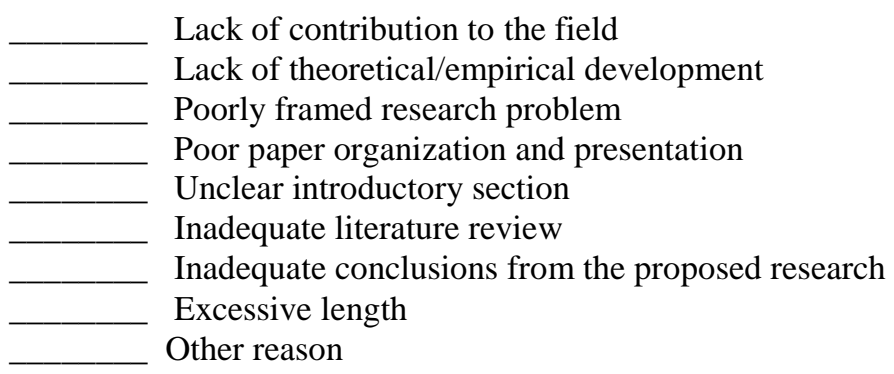

2. Please rank in order of frequency (up to 9, if applicable) of the types of papers that are accepted at your journal.

Theoretical developments
Conceptual developments
Analytical developments
Literature reviews
Position papers
Responses to already published research
Case studies
Book reviews
Educational (or how-to) papers

\section{Questions on Publication Timeline}

1. What is the average time length for the entire review process from $1^{\text {st }}$ submission to acceptance - including subsequent revisions (in months)?
a. less than 6 months
b. 6-12 months
c. $12-18$ months
d. 18-24 months
e. greater than 24 months

2. What is the average time length from accepted papers to print (in months)?
a. less than 6 months
b. 6-12 months
c. 12-18 months
d. $18-24$ months
e. greater than 24 months

3. What is the average time length for the initial editor review process (in months)?
a. less than 1 month
b. 1-3 months
c. 3-5 months
d. 5-7 months
e. greater than 7 months 
4. What is the average time length for the peer review process (in months)?
a. less than 2 months
b. 2-4 months
c. $4-6$ months
d. 6-8 months
e. greater than 8 months

5. What is the average time length for the decision to either accept, revise, or reject, after receipt of the reviewer's recommendation (in months)?
a. less than 1 month
b. 1-3 months
c. 3-5 months
d. 5-7 months
e. greater than 7 months

\section{Open-Ended Questions}

1. Are you willing to conduct a follow-up interview with the National Science Foundation investigators? If yes, please provide your name, school, and email address.

2. In two or less sentences, what is your description of an ideal journal paper?

3. What advice would you provide young researchers as they prepare to begin the journal publication process?

4. Have you observed any barriers in the publication process that impact the acceptance of women researchers' papers? If so, would you elaborate?

5. What, if any, additional or unique advice would you give to women researchers concerning a successful publication practice (versus advice given to male researchers)? 
NOTES 